\title{
Different Array CGH profiles within hereditary breast cancer tumors associated to BRCA1 expression and overall survival
}

Carolina Alvarez ${ }^{1}$, Andrés Aravena 2,8, Teresa Tapia ${ }^{1}$, Ester Rozenblum³ ${ }^{3}$, Luisa Solís ${ }^{4}$, Alejandro Corvalán ${ }^{4}$,

Mauricio Camus ${ }^{5}$, Manuel Alvarez ${ }^{6}$, David Munroe ${ }^{3}$, Alejandro Maass ${ }^{2,7}$ and Pilar Carvallo ${ }^{1 *}$

\begin{abstract}
Background: Array CGH analysis of breast tumors has contributed to the identification of different genomic profiles in these tumors. Loss of DNA repair by BRCA1 functional deficiency in breast cancer has been proposed as a relevant contribution to breast cancer progression for tumors with no germline mutation. Identifying the genomic alterations taking place in BRCA1 not expressing tumors will lead us to a better understanding of the cellular functions affected in this heterogeneous disease. Moreover, specific genomic alterations may contribute to the identification of potential therapeutic targets and offer a more personalized treatment to breast cancer patients.

Methods: Forty seven tumors from hereditary breast cancer cases, previously analyzed for BRCA1 expression, and screened for germline BRCA1 and 2 mutations, were analyzed by Array based Comparative Genomic Hybridization $(\mathrm{aCGH})$ using Agilent 4x44K arrays. Overall survival was established for tumors in different clusters using Log-rank (Mantel-Cox) Test. Gene lists obtained from aCGH analysis were analyzed for Gene Ontology enrichment using GOrilla and DAVID tools.
\end{abstract}

Results: Genomic profiling of the tumors showed specific alterations associated to BRCA1 or 2 mutation status, and BRCA1 expression in the tumors, affecting relevant cellular processes. Similar cellular functions were found affected in BRCA1 not expressing and BRCA1 or 2 mutated tumors. Hierarchical clustering classified hereditary breast tumors in four major, groups according to the type and amount of genomic alterations, showing one group with a significantly poor overall survival ( $p=0.0221$ ). Within this cluster, deletion of PLEKHO1, GDF11, DARC, DAG1 and CD63 may be associated to the worse outcome of the patients.

Conclusions: These results support the fact that BRCA1 lack of expression in tumors should be used as a marker for BRCAness and to select these patients for synthetic lethality approaches such as treatment with PARP inhibitors. In addition, the identification of specific alterations in breast tumors associated with poor survival, immune response or with a BRCAness phenotype will allow the use of a more personalized treatment in these patients.

Keywords: Breast cancer, BRCAX, Array CGH, Tumor suppressor, Oncogenes, Genomic losses, Genomic gains

\footnotetext{
* Correspondence: pcarvallo@bio.puc.cl

'Department of Cellular and Molecular Biology, Faculty of Biological Sciences,

Pontificia Universidad Católica de Chile, Santiago, Chile

Full list of author information is available at the end of the article
} 


\section{Background}

Breast cancer is the first cause of female death by neoplasm around the world. In Chile, mortality rate due to breast cancer is in first place with 15.5/100.000 women (DEIS, MINSAL 2011). As all cancers, it has been described that breast cancer is driven by several alterations in tumor suppressor genes and oncogenes. Within these alterations, somatic mutations [1], gene deletion or duplication, and promoter hypermethylation [2] are described as the most frequent mechanisms occurring in cancer, and contributing to neoplastic progression [3, 4]. Mutations or alterations in tumor suppressor genes such as gene or chromosomal deletions can be found at different frequencies between tumors, being possible to find a cancer driver alteration in a low proportion of tumors [4]. Several methodologies, as next generation sequencing and array-CGH, are being used in order to detect and identify these mutations and rearrangements. Comparative genomic hybridization (CGH) and, more recently, array-based $\mathrm{CGH}$ have been extensively used in the analysis of gains and losses in tumor DNA $[5,6]$. Among the most common genomic alterations described in sporadic and hereditary breast tumors are losses at chromosomes 8p, 11q, 13q and 17p; and gains within chromosomes 1q, 8q, 17q and 20q [7-12]. Through the years, several groups have intended to associate genomic alterations with different breast tumor characteristics. Regarding hereditary tumors, which are the focus of this study, the main findings relay on the association of genomic instability levels with the presence of BRCA1/2 abnormalities $[8,13,14]$ or with immunohistochemical phenotypes [15]. In this sense, tumors with $B R C A 1 / 2$ mutations, BRCA1 promoter hypermethylation/loss of expression, and "basal like" phenotype are shown to have higher instability. These findings are in coherence with BRCA1 and BRCA2 nuclear role in DNA repair, and support their relevance, not only for cancer predisposition, but also for cancer progression. These studies add important and valuable information to the field, nevertheless the complexity and genetic heterogeneity of breast cancer, and the genetic heterogeneity of worldwide populations, support the need of further studies expanding in the analysis of hereditary tumors.

Loss of BRCA1 expression has been described to be associated frequently to $\mathrm{LOH}$ [16] and promoter hypermethylation $[13,16,17]$ in sporadic and hereditary cases. Few somatic mutations have been found recently for these genes. More recently, miRNA regulation of BRCA1 mRNA stability appears as a new mechanism contributing to BRCA1 silencing [18-20]. Interestingly, little has been done investigating genomic profiles in breast cancer tumors in association with BRCA1 expression. These studies have been mainly directed to triple negative sporadic breast cancer tumors [13, 21, 22].
The aim of the present work is to evaluate the genomic profiles of a Chilean subset of hereditary breast cancer tumors by array-CGH, highlighting the different alterations found in tumors with loss of BRCA1 expression, and in tumors with germline BRCA mutations. In addition, we identified hereditary tumors clusters in groups with different levels of genomic instability, and significant differences in overall survival. We identified particular genomic alterations in BRCA1 not expressing tumors relevant to functions associated with BRCA1/2 mutated tumors.

\section{Methods}

\section{Patients and tumors}

Families were previously selected from 1999 to 2004 from three health centers in Santiago, using standard criteria for hereditary breast cancer: 1) three women with breast cancer in at least two consecutive generations, 2) two women with breast cancer, one of them diagnosed before age of 41 and 3) at least one woman with breast and one with ovarian cancer [23]. All patients signed a written informed consent for the publication of clinical data and BRCA1 and BRCA2 mutational screening results. This protocol was approved by the Ethics Committee at the Faculty of Medicine, Pontificia Universidad Catolica de Chile. All patients were screened for BRCA1 and BRCA2 germline mutations as described by Gallardo et al [23]. A total of 47 formalinfixed paraffin embedded (FFPE) tumor biopsies from surgically resected breast cancer tissue were collected from these patients. In this study, forty biopsies belong to BRCAX patients (hereditary cases with no BRCA1/2 germline mutations), 3 to $B R C A 1$ patients and 4 to $B R C A 2$ patients.

\section{Immunohistochemistry}

The histological type and grade of the tumors were classified according to the World Health Organization. Paraffin sections were processed for the detection of Estrogen Receptor (ER) and HER2 expression by immunohistochemistry at the Anatomo-Pathology department at clinical assessment. Briefly, $4 \mu \mathrm{m}$ tumor sections were deparaffinized and re-hydrated prior to antigen unmasking with EDTA pH 8.0. Automated immunohistochemical staining was carried out using the BioGenex i $6000^{\mathrm{m}}$ Automated Staining System and the streptavidin-biotin complex $(s A B C)$ peroxidase method with DAB substrate (3, 3'- diaminobenzidine). Presence of ER and HER2 was evaluated using the following antibodies: anti-ER clone 6 F11 (1:40 dilution, Novocastra), and anti-HER2 clone CB11 (1:100 dilution, Novocastra). The interpretation of the slides was done in an independent manner by two pathologists. For ER and PR, positivity was scored as $1 \%$ or more of the examined area positively stained, as 
established by the American Society of Clinical Oncology and the College of American Pathologists (ASCO/ CAP). For HER2, scores 0 and $1+$ indicate negativity and $2+$ and $3+$ positivity. In addition, we previously performed immunohistochemical detection of BRCA1 for our cohort of hereditary tumors [17].

\section{DNA extraction}

Between 5000 and 10,000 tumor cells were manually microdissected from $5 \mu \mathrm{m}$ Hematoxilin-Eosin (H\&E) breast tumor sections, and collected into a sterile tube. DNA was extracted by Proteinase $\mathrm{K}$ digestion $(0.4 \mathrm{mg} / \mathrm{ml}$ Proteinase $\mathrm{K}, 1 \mu \mathrm{M}$ EDTA, $0.02 \mathrm{M}$ Tris, $0.5 \%$ Tween 20) for $48 \mathrm{~h}$ at $37{ }^{\circ} \mathrm{C}$ in a water bath under gentle shaking. After digestion, each DNA was precipitated with ethanol. In order to minimize the interference of polymorphic copy number variants $(\mathrm{CNV})$, we prepared reference DNA from normal cells obtained from $H \& E$ sections of healthy lymph node biopsies from 6 of the analyzed $B R C A X$ patients. Extracted DNA was quantified using a NanoDrop spectrophotometer (Thermo Fisher Scientific, DE).

\section{Array CGH}

Ten to twenty nanograms of genomic DNA of each sample and reference were amplified with Phi29 DNA polymerase according to the supplier's protocol (GenomiPhi, GE Healthcare). After verification of amplified product in a $0.8 \%$ agarose gel we performed restriction digestion in order to obtain fragmented DNA of a suitable size for hybridization. All digestions were done with both AluI and RsaI for $4 \mathrm{~h}$ at $37{ }^{\circ} \mathrm{C}$. Labeling reactions were performed with 6-8 $\mu \mathrm{g}$ of purified digested DNA using Bioprime $\mathrm{CGH}$ labeling kit (Invitrogen) according to the manufacturer's instructions. The only variation was the extension of the labeling time to $18 \mathrm{~h}$. Test DNA was labeled with Cy3-dUTP and reference DNA with Cy5dUTP. Samples were then cleaned using MicroBioSpin6 Columns (BioRad) followed by ethanol precipitation. Specific activity of each fluorophore was estimated for all samples using a NanoDrop spectrophotometer (Thermo Fisher Scientific, DE). Equal amounts of test and reference labeled DNA (total volume of $50 \mu \mathrm{l}$ ) were mixed with $5 \mu \mathrm{g}$ of Human Cot-1 DNA and 2X hybridization buffer (dextran sulfate $10 \%$, 3X SSC and Tween $201.5 \%$ ). Samples were hybridized under rotation for $40 \mathrm{~h}$ at $65{ }^{\circ} \mathrm{C}$ using a hybridization oven. Arrays were washed according to supplier's protocol (Agilent Technologies).

\section{Oligonucleotide microarray platform}

We used the Agilent oligonucleotide 4x44K microarrays for the array-based CGH analyses. This platform is based on the UCSC hg18 human genome (NCBI Build 36) and consists of 45,000 probes mainly directed to codifying sequences. All probes are 60mer oligonucleotides with an average spatial resolution of $43 \mathrm{~Kb}$.

\section{Analyses}

The hybridized microarrays were scanned with a GenePix 4100A scanner (Molecular Devices) and signal processing was done with either Feature Extraction software (Agilent Technologies) or GenePix Pro (Molecular Devices). Raw data was normalized using $\mathrm{R}$ package CGHnormaliter from Bioconductor (http://www.bioconductor.org/packages/2.6/bioc/html/CGHnormaliter.html). Deletions and gains were identified with DNA Analytics (Genomic Workbench, Agilent Technologies) using the ADM-1 (Aberration Detection Method-1) algorithm with a $\log 2$ ratio filter of 0.2 , and a threshold of 4.0 .

\section{Availability of data}

The dataset supporting the conclusions of this articles is available in the Gene Expression Omnibus repository (http://www.ncbi.nlm.nih.gov/geo, accession number GSE70541)

\section{Hierarchical clustering}

Using aberrations called by DNA Analytics we clustered our samples using R 'hclust' function with complete linkage. Every probe in each sample was represented by a nominal variable taking one of three values: loss, unaltered or gain. Then we used Hamming distance to compare samples, that is, we counted the number of probes in which two samples disagree. To avoid false positives induced by noise, we only considered probes that where altered on three or more samples. We examined the resulting hierarchical clustering and we found that the most informative partition was the one in four disjoint groups with similar size. We performed overall survival analysis to 10 years before census using Logrank (Mantel-Cox) Test considering data available from all patients. Statistical significance was considered with a $p$ value $<0.05$.

\section{Genomic instability of the tumors}

For each tumor, total number of losses and gains were determined based upon called aberrations breakpoints identified by ADM-1. Using Student $t$-test we compared the genomic instability among the four clusters: Blue, Yellow, Green and Purple.

\section{Gene Ontology analyses}

We performed ontological analyses with Gorilla [24] and DAVID [25] tools using gene lists obtained from the array-CGH analysis for different hereditary tumor groups: BRCA1 or BRCA2 mutated, BRCA1 not expressing, BRCA1 expressing, and clusters. 


\section{Results}

We analyzed 47 hereditary breast cancer tumors by array-CGH and found different alterations in relation to $B R C A 1$ and BRCA2 mutation status, and to BRCA1 protein expression.

Tumor features and receptors status are specified in Table 1. Figure 1 shows a graphical representation of all probes involved in gained or lost regions across all chromosomes, and the number of tumors carrying such alterations; we observed that compared to gains, a greater number of deletions are present in unique tumors revealing heterogeneity at this level.

\section{Genomic losses and gains in BRCAX breast cancer tumors}

Tables 2 and 3 show a list of losses and gains present in more than $10 \%$ of BRCAX tumors including the most frequent alterations highlighted in bold. In each table, candidate "tumor suppressor genes" or "oncogenes" are indicated. The two most frequent genomic losses are present concomitantly in 9 BRCAX tumors $(22.5 \%$ in Table 2). It is relevant that 9 tumors have a deletion of two genes previously related to cancer progression such as PLEKHO1 [26] a negative regulator of the mitogenic PI3K/AKT signaling pathway and $A P H 1 A$ [27] which loss of expression has been associated to poor survival in triple negative breast cancer patients [27]. Interestingly, a second group of tumors (15\% in Table 2) presented deletions at 9 regions simultaneously, all of them including several genes previously associated to cancer such as PSMB8 [28], HLA-DMB [29], SSBP1 [30] and CADM1 [31].

The most frequent gains found in our BRCAX tumors (Table 3) have been previously observed to be amplified in breast cancer $[7,8,12]$, and contain at least four genes of interest PDE4DIP/Myomegalin [32, 33], IL19, IL20 [34-36] and FAIM3 [37-39]. The gain of these regions is in agreement with the overexpression observed in breast tumors for all these genes. Specially, IL19 has been proposed as a prognostic marker in breast cancer, and its expression is correlated to advanced tumor stage, metastasis, and poor survival $[34,36]$. In this way, targeting IL19 could become a good therapy for breast cancer patients.

\section{Specific genomic alterations in hereditary tumors from BRCA1 and BRCA2 mutation carriers}

In order to find specific alterations for $B R C A 1$ and $B R C A 2$ mutated tumors, we filtered out all those present in BRCAX tumors. Table 4 shows the genomic losses and gains present only in BRCA1 and BRCA2 tumors, highlighting in bold the genes already associated to cancer. Our analysis showed that DNA samples from BRCA1 and BRCA2 tumors carry common alterations (3/7 tumors), which are mainly deletions. We admit that our sample of seven $B R C A 1$ and 2 germline mutated tumors is small, but we felt important to highlight recurrent genomic alterations, not present in BRCAX tumors, since this has not been described in previous studies. Interestingly, one of these genes, E2F6, acts as a repressor of BRCA1 transcription [40, 41]. The overexpression of this transcriptional repressor in breast tumors may be a relevant mechanism for BRCA1 silencing.

Interestingly, tumors with the same $B R C A 2$ mutation T5 and T50 have a common genomic profile (Table 4). This is in line with a previous study by Alvarez et al [14], where they show that tumors with the same recurrent mutation in BRCA2 share similar alterations. One alteration in these tumors that caught our attention was the $3 \mathrm{Mb}$ loss in chromosome 4 , which comprise at least three genes relevant for tumor suppression: NEK1, POSH and ANX10A (Table 4) [42-44]. These genes participate either in DNA repair and checkpoint control, apoptosis or in the regulation of cell proliferation, adding other crucial targets for cancer progression besides BRCA1 and BRCA2 dependent DNA repair.

In addition to the specific alterations, we found an interesting deletion at $3 \mathrm{p} 12$ in three BRCA2 mutated tumors involving the genes for ROBO receptors 1 and 2 . These genes encode for receptors of the SLIT/ROBO pathway, demonstrated to promote tumor suppression in breast cancer cell lines by impairing AKT/PI3K signaling [45]. On the other hand, some BRCAX tumors present loss of SLIT2 loci, a ROBO ligand. Both results together strongly suggest that the inactivation of this pathway is necessary for the progression of $B R C A 2$ and BRCAX tumors. In a previous work from our group [46] we found a high percentage of hereditary tumors with loss of SLIT2 protein expression related to the hypermethylation of its promoter. These findings support the relevance of the silencing of the SLIT/ROBO pathway for the progression of hereditary breast cancer.

\section{BRCA1 expression and genomic alterations in hereditary breast tumors}

We have previously evaluated BRCA1 protein expression in these tumors through immunohistochemistry [17]. We found twenty four tumors with a negative expression of BRCA1 in the nucleus, two of them carrying a germline $B R C A 1$ mutation. Among the tumors with no BRCA1 mutations and loss of BRCA1 expression, we found $67 \%$ with $B R C A 1$ promoter hypermethylation [17]. In addition, specific analysis of the BRCA1 probes of the array in this study (data not shown) revealed partial or total deletion of BRCA1 in 7 BRCA1 not expressing tumors (29\%). Since BRCA1 is a relevant driver in breast cancer we analyzed gains and losses in these tumors 
Table 1 Hereditary tumors, histopathological features and cancer family history

\begin{tabular}{|c|c|c|c|c|c|c|c|c|c|}
\hline \multirow[t]{2}{*}{$\begin{array}{l}\text { Tumor } \\
\text { ID }\end{array}$} & \multirow[t]{2}{*}{$\begin{array}{l}\text { Histological } \\
\text { type }\end{array}$} & \multirow[t]{2}{*}{$\begin{array}{l}\text { Tumor } \\
\text { grade }\end{array}$} & \multicolumn{4}{|c|}{$\mathrm{IHC}$} & \multicolumn{2}{|c|}{$\begin{array}{l}\text { Mutation } \\
\text { detected }\end{array}$} & \multirow[t]{2}{*}{ Family History } \\
\hline & & & ER & PR & HER2 & BRCA1 & BRCA1 & BRCA2 & \\
\hline T6 & IDC & III & - & - & - & - & & & 4 breast, 1 esophageal cancer \\
\hline $\mathrm{T} 10$ & IDC & III & - & - & - & - & & & 2 breast, 1 prostate cancer \\
\hline $\mathrm{T} 11$ & IDC & III & - & - & - & - & & & 1 breast bilateral with ovarian cancer \\
\hline $\mathrm{T} 12$ & IDC & $\|$ & - & + & - & - & & & 2 breast OR 1 breast, 1 ovarian, 1 stomach cancer \\
\hline $\mathrm{T} 17$ & IDC & III & - & - & - & - & & & 2 breast, 1 uterine, 1 testicular cancer \\
\hline $\mathrm{T} 20$ & LCIS & - & - & - & $1+$ & - & & & 3 breast, 1 stomach cancer \\
\hline T24 & IDC & $\|$ & - & - & - & - & YES & & 1 bilateral and 2 breast, 1 gallbladder cancer, 1 melanoma \\
\hline T39 & IDC & III & - & - & - & - & & & 1 bilateral and 3 breast cancer, 1 uterine, 1 stomach cancer \\
\hline T41 & IDC & III & - & - & - & - & & & 4 breast, 2 stomach, 1 prostate cancer \\
\hline T42 & IDC & III & - & - & - & - & & & 4 breast, 2 stomach, 1 prostate cancer \\
\hline T43 & IDC & III & - & - & - & - & & & 4 breast, 2 stomach, 1 prostate cancer \\
\hline T45 & IDC & $\|$ & - & + & - & - & & & 1 bilateral breast, 4 breast, 1 testicular cancer \\
\hline $\mathrm{T} 25$ & IDC & III & + & + & - & - & YES & & 1 bilateral and 2 breast, 1 gallbladder cancer, 1 melanoma \\
\hline $\mathrm{T} 1$ & IDC & III & + & - & $1+$ & - & & & 5 breast, 1 stomach, 1 gallbladder, 1 other cancer \\
\hline T3 & IDC & III & + & + & - & - & & & 2 breast, 1 uterine, 1 gallbladder, 1 esophageal cancer, 2 other cancer \\
\hline T26 & IDC & III & + & + & - & - & & & 6 breast, 1 stomach cancer, 1 leukemia \\
\hline T29 & IDC & $\|$ & + & + & $1+$ & - & & & 5 breast, 1 liver, 2 stomach cancer \\
\hline T32 & IDC & I & + & + & - & - & & & 3 breast, 1 prostate, 1 uterine cancer \\
\hline T35 & IDC & । & + & + & - & - & & & 5 breast, 1 bilateral breast, 1 stomach, 1 pancreatic cancer \\
\hline T36 & IDC & I & + & + & - & - & & & 3 breast cancer \\
\hline T37 & IDC & $\|$ & + & + & - & - & & & 4 breast (1 bilateral), 1 testicular, 1 other cancer \\
\hline T9 & LCIS & - & + & + & $3+$ & - & & & 4 breast (1 breast/colon), 3 stomach, 2 prostate, 1 pancreatic cancer \\
\hline T15 & IDC & $\|$ & + & + & $2+$ & - & & & 3 breast cancer, one in a male \\
\hline T21 & ILC & - & + & + & $2+$ & - & & & 3 breast, 1 stomach, 1 other cancer \\
\hline T4 & IDC & I & - & + & - & + & & & 3 breast cancer \\
\hline T5 & IDC & III & - & - & - & + & & YES & 2 breast, 1 stomach cancer, 1 leukemia \\
\hline T16 & IDC & I & - & + & - & + & & & 2 breast, 1 uterine, 1 stomach cancer \\
\hline T23 & IDC & III & - & - & - & + & & & 1 breast, 1 prostate OR 1 breast, 1 stomach, 1 other cancer \\
\hline T19 & LCIS & - & - & + & $2+$ & + & & & 3 breast, 1 stomach cancer \\
\hline T46 & IDC & III & - & - & $3+$ & + & & & 1 bilateral and 1 breast cancer \\
\hline T44 & DCIS & - & + & + & - & + & & YES & 1 bilateral and 3 breast cancer, 1 ovarian cancer, 1 stomach, 1 other cancer \\
\hline T49 & IDC & $\|$ & + & + & - & + & YES & & 1 bilateral breast, 1 uterine cancer(abuela paterna) \\
\hline $\mathrm{T} 2$ & DCIS & - & + & + & - & + & & & 2 breast, 1 liver cancer \\
\hline T8 & $\mathrm{ILC}$ & - & + & - & - & + & & & 1 bilateral breast cancer \\
\hline $\mathrm{T} 13$ & DCIS & - & + & + & - & + & & & 3 breast, 1 uterine, 2 stomach cancer \\
\hline $\mathrm{T} 22$ & IDC & $\|$ & + & + & - & + & & & 2 breast, 2 ovarian, 1 lung cancer, 1 lymphoma \\
\hline T28 & DCIS & - & + & + & $1+$ & + & & & 3 breast cancer, 1 esophageal cancer \\
\hline $\mathrm{T} 30$ & ILC & - & + & + & $1+$ & + & & & 3 breast, 1 lymphoma \\
\hline T31 & IDC & I & + & + & - & + & & & 3 breast, 1 prostate, 1 uterine cancer \\
\hline T33 & IDC & III & + & + & - & + & & & 5 breast, 1 bilateral breast, 1 stomach, 1 pancreatic cancer \\
\hline T34 & IDC & $\|$ & + & + & - & + & & & 5 breast, 1 bilateral breast, 1 stomach, 1 pancreatic cancer \\
\hline T38 & LCIS & - & + & + & - & + & & & 4 breast (1 bilateral), 1 testicular, 1 other cancer \\
\hline
\end{tabular}


Table 1 Hereditary tumors, histopathological features and cancer family history (Continued)

\begin{tabular}{|c|c|c|c|c|c|c|c|c|}
\hline $\mathrm{T} 47$ & IDC & $\|$ & + & + & - & + & & 2 breast, 1 prostate OR 2 breast, 1 stomach cancer \\
\hline T48 & IDC & III & + & - & - & + & & 3 breast cancer \\
\hline T14 & DCIS & - & + & + & $2+$ & + & & 5 breast cancer \\
\hline T51 & IDC & $\|$ & + & + & ND & ND & YES & 2 breast, 1 stomach cancer, 1 colon cancer, 1 myeloma \\
\hline T50 & IDC & III & + & - & $1+$ & ND & YES & 2 breast, 1 stomach cancer \\
\hline
\end{tabular}

IDC Invasive Ductal Carcinoma, ILC Invasive Lobular Carcinoma, DCIS Ductal Carcinoma in situ, LCIS Lobular Carcinoma in situ ND Not determined

to correlate the absence of BRCA1 protein to specific genomic alterations. On this respect, we found several recurrent deletions private for BRCA1 not expressing tumors: 1p36.13, 8p22, 9q32, 11q14.1, $11 \mathrm{q} 23.3,13 \mathrm{q} 12.13,15 \mathrm{q} 22.33,17 \mathrm{p} 12$, previously described in hereditary breast cancer tumors $[8,14,15$, 22]. Two of these regions, $9 \mathrm{q} 32$ and $13 \mathrm{q} 12$, have been described also for BRCA1 germline mutated tumors [12, 13]. In relation to this study, 8 p22 region with at least six candidate tumor suppressor genes, was found lost in 4/24 BRCA1 not expressing tumors. Downregulation of four of these genes (TUSC3, DLC1, ZDHHC2 and MTUS1) have been described associated to invasiveness and metastasis [47-50].

On the other hand a 3.6 Mbp gain in chromosome 12q21.1, including oncogenes LGR5 (leucine-rich repeat containing G protein-coupled receptor 5) and RAB21 (RAB21, member RAS oncogene family), was the most frequent gain found in BRCA1 not expressing tumors. Interestingly, in addition to the 4 genes described before, RAB21 has also been implicated in the invasiveness and metastasis of breast cancer cells in vitro [51].

\section{Clustering analysis revealed four major groups of hereditary tumors}

In order to identify the major rearrangements that characterize different hereditary tumors we clustered our samples into four groups using array CGH data. Figure 2a shows four major groups of tumors characterized by the type of alteration (loss or gain), the amount of alterations, and/or their size. The Blue and Yellow clusters carry mainly deletions that clearly distinguished these tumors. Most of these alterations are shown in Table 2, and include genes associated to immune response (Blue) and cell cycle regulation (Yellow). The Purple cluster tumors carry mainly gains involving genes associated to migration, invasion and metastasis in breast and other cancers. Finally, the Green cluster is a more heterogeneous group, characterized by tumors carrying a significant lower number of gains and/or losses compared to the other clusters (Student $T$-test, $p$ values $=$ Blue vs Green 0.00029, Yellow vs Green 0.003106, Purple vs Green 0.004513).

Interestingly, regarding receptor status and tumor clustering, five of the seven (71.4 \%) HER2 positive tumors were grouped in the Purple cluster (Fig. 2a), and

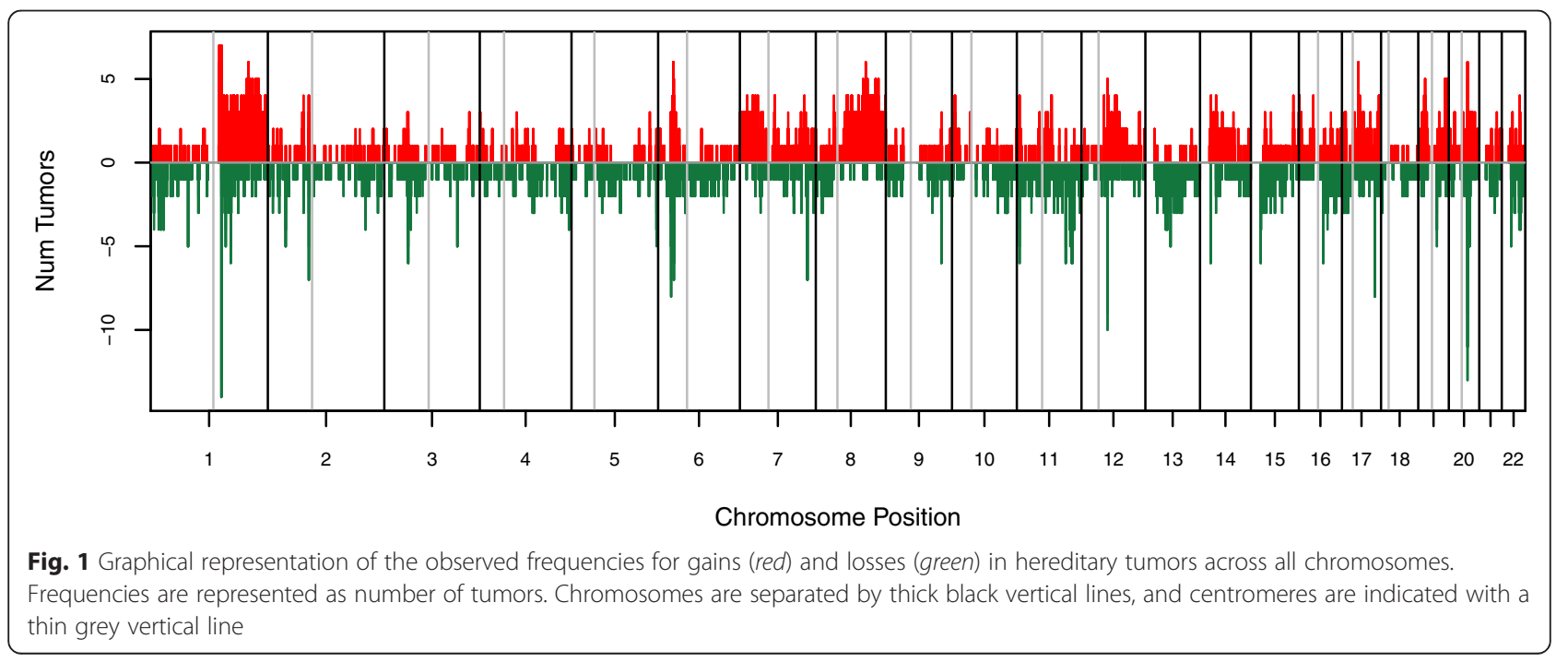


Table 2 Genomic losses found in more than $10 \%$ of BRCAX breast tumors

\begin{tabular}{|c|c|c|c|c|c|c|c|}
\hline Chromosome & CytoBand & Start & Stop & Size bp & $\begin{array}{l}\text { Percentage of BRCAX } \\
\text { tumors }(N=40)\end{array}$ & $\begin{array}{l}\text { Candidate tumor } \\
\text { suppressor genes }\end{array}$ & Other genes \\
\hline \multirow[t]{3}{*}{1} & p31.1 & 78765816 & 79106841 & 341,025 & 12.5 & & PTGFR, IFI44L, IFI44 \\
\hline & $\mathrm{q} 21.2$ & 148392365 & 148504936 & 112,571 & 22.5 & PLEKHO1, APH1A & ANP32E, CA14 \\
\hline & q24.2 & 167969938 & 168079511 & 109,573 & 12.5 & & C1orf156, C1orf112 \\
\hline 3 & q25.1 & 152529936 & 152650652 & 120,716 & 12.5 & & MED12L,P2RY13, P2RY12, IGSF10 \\
\hline \multirow[t]{4}{*}{6} & p21.32 & 32897974 & 32905723 & 7749 & 15.0 & & TAP2 \\
\hline & p21.32 & 32918832 & 32929682 & 10,850 & 17.5 & PSMB8 & TAP1 \\
\hline & p21.32 & 32932575 & 33057062 & 124,487 & 15.0 & HLA-DMB & PSMB9, BRD2 \\
\hline & p22.1 & 27200902 & 27210109 & 9207 & 20.0 & & HIST1H2BJ, HIST1H2AG \\
\hline 7 & q34 & 141051502 & 141137338 & 85,836 & 17.5 & SSBP1 & WEE2, TAS2R3, TAS2R4, TAS2R5 \\
\hline 9 & q32 & 116094655 & 116176804 & 82,149 & 15.0 & & COL27A1, ORM1, ORM2, AKNA \\
\hline 11 & q23.3 & 114614479 & 116165823 & $1,551,344$ & 15.0 & CADM1 & BUD13, ZPR1, APOA5 \\
\hline 12 & q13.2 & 54429832 & 54500555 & 70,723 & 12.5 & & GDF11, CIP29, ORMDL2 \\
\hline 13 & q21.1 & 52406170 & 52944596 & 538,426 & 12.5 & & OLFM4 \\
\hline 14 & $q 11.2$ & 22424322 & 22467920 & 43,598 & 15.0 & & REM2, RBM23, PRMT5 \\
\hline 15 & $q 11.2$ & 20477397 & 20599137 & 121,740 & 15.0 & CYFIP1 & NIPA2, NIPA1 \\
\hline 16 & q12.1 & 50773858 & 51032886 & 259,028 & 15.0 & & TOX3 \\
\hline 17 & $\mathrm{q} 25.1$ & 68713135 & 68845671 & 132,536 & 20.0 & & $\begin{array}{l}\text { COG1, FAM104A, C17orf80, } \\
\text { CDC42EP4, SDK2 }\end{array}$ \\
\hline \multirow[t]{2}{*}{20} & $q 12$ & 39100100 & 39142168 & 42,068 & 22.5 & & TOP1 \\
\hline & $q 12$ & 39201874 & 39331155 & 129,281 & 12.5 & & PLCG1, ZHX3 \\
\hline 22 & $q 11.21$ & 19683237 & 19692296 & 9059 & 12.5 & & LZTR1, THAP7 \\
\hline
\end{tabular}

Most frequent losses in BRCAX tumors are highlighted in bold

none were contained in the large Green cluster. ER positive tumors instead were distributed equitably along the four groups, as well as BRCA1 not expressing tumors.

We performed overall survival analysis using Logrank (Mantel-Cox) Test considering data available from all patients (Fig. 2b). Analysis of the four groups revealed a significant poor survival at 10 years after surgery, for patients carrying tumors in the yellow cluster $(p$ value $=0.0221)$.

\section{Gene ontology enrichment}

Analysis with GOrilla [24] and DAVID [25] showed different cellular processes affected in different groups of tumors (Table 5). In BRCA1/2 mutated and BRCA1 not expressing tumors, both having an impaired DNA double strand break repair, we found common cellular processes affected such as apoptosis, chromatin organization/DNA packaging and transcription. These results suggest that breast cancer tumors with nonfunctional BRCA1, due to any of the mentioned factors, share the impairment of the same cellular processes caused by BRCA1 absence or deficiency.

Considering the four clusters, distinct processes were identified indicating different tumor progression programs (Table 5). No significant enrichment was found within the green cluster. As previously mentioned, the Yellow cluster showed a poor survival compared to the rest of the tumor clusters. Within the enriched processes affected in these tumors we found two relevant genes, $D A R C$ (Duffy antigen receptor for chemokines) and DAG1 ( $\alpha$-Dystroglycan). The loss of expression of these genes has been associated with poor survival of breast cancer patients [52-54]. This association is probably due to the aggressiveness and metastatic potential that tumor cells acquire in the absence of the function of these genes.

\section{Discussion}

We analyzed through array CGH the genomic profile of 47 biopsies, from hereditary breast cancer patients, 40 from $B R C A X$ patients, 3 from $B R C A 1$ and 4 from $B R C A 2$ mutation carriers (Table 1). To our knowledge this is the first study on genomic alterations, gene functions and molecular pathways involved in hereditary breast cancer tumors, in a Latin American population. The relevance of this study is based on the influence of Genetics and Environment as two key factors in cancer progression.

We found several chromosomal alterations with low frequency in hereditary breast cancer tumors, 
Table 3 Genomic gains found in more than $10 \%$ of BRCAX breast tumors

\begin{tabular}{|c|c|c|c|c|c|c|c|}
\hline Chromosome & CytoBand & Start & Stop & Size bp & $\begin{array}{l}\text { Percentage } \\
\text { of BRCAX } \\
\text { tumors } \\
(N=40)\end{array}$ & $\begin{array}{l}\text { Candidate } \\
\text { oncogenes }\end{array}$ & Other genes \\
\hline \multirow[t]{13}{*}{1} & q21.1 & 143706304 & 143905470 & 199,166 & 15.0 & PDE4DIP & SEC22B \\
\hline & q21.1 & 144219515 & 144279910 & 60,395 & 12.5 & RBM8A & GNRHR2, PEX11B, ITGA10, ANKRD35 \\
\hline & $q 21.2$ & 148240535 & 148367347 & 126,812 & 12.5 & OTUD7B & VPS45 \\
\hline & $\mathrm{q} 21.2$ & 148392365 & 148504936 & 112,571 & 17.5 & & PLEKHO1, APH1A, ANP32E, CA14 \\
\hline & $\mathrm{q} 21.2$ & 148519890 & 148564234 & 44,344 & 15.0 & & C1 orf54, C1 orf51, MRPS21, PRPF3 \\
\hline & q32.1 & 201456918 & 201966787 & 509,869 & 12.5 & BTG2 & CHIT1, FMOD, ATP2B4 \\
\hline & q32.1 & 202269067 & 202358437 & 89,370 & 12.5 & & C1orf157, SOX13 \\
\hline & q32.1 & 205037481 & 205260296 & 222,815 & 15.0 & $\begin{array}{l}\text { IL19, IL20, } \\
\text { FAIM3 }\end{array}$ & IL24, PIGR, FCAMR, C1orf116 \\
\hline & q32.2 & 205762617 & 206263053 & 500,436 & 12.5 & CD46, PLXNA2 & CR1, CR1L, CD34 \\
\hline & q32.2 & 207826895 & 208566054 & 739,159 & 12.5 & TRAF3IP3,LAMB3 & $\begin{array}{l}\text { G0S2, HSD11B1, C1 orf74, IRF6, C1 orf107, SYT14, } \\
\text { SERTAD4 }\end{array}$ \\
\hline & q41 & 213425725 & 213768607 & 342,882 & 12.5 & & KCNK2 \\
\hline & $\mathrm{q} 42.12$ & 223406336 & 224419278 & $1,012,942$ & 12.5 & ENAH, LBR & $\begin{array}{l}\text { DNAH14, SRP9, EPHX1, TMEM63A, LEFTY1, PYCR2, } \\
\text { LEFTY2, C1 orf55, H3F3A, ACBD3 }\end{array}$ \\
\hline & $q 42.13$ & 225961050 & 226071970 & 110,920 & 12.5 & & JMJD4, SNAP47, MPN2 \\
\hline 6 & p21.33 & 31663820 & 31905687 & 241,867 & 12.5 & CLIC1, CSNK2B & $\begin{array}{l}\text { LST1, NCR3, AIF1, BAT2, BAT3, APOM, BAT4, } \\
\text { C6orf47, LY6G5B, LY6G5C, BAT5, LY6G6F, LY6G6E, } \\
\text { LY6G6D, LY6G6C, DDAH2, MSH5, C6orf27, VARS, } \\
\text { LSM2, HSPA1A, HSPA1B }\end{array}$ \\
\hline \multirow[t]{5}{*}{8} & q22.1 & 98923270 & 99014727 & 91,457 & 12.5 & LAPTM4B & MATN2 \\
\hline & q22.3 & 104310836 & 104453937 & 143,101 & 12.5 & FZD6, CTHRC1 & BAALC \\
\hline & q23.1 & 107173263 & 107833235 & 659,972 & 12.5 & & OXR1 \\
\hline & $q 24.13$ & 124926272 & 125341753 & 415,481 & 12.5 & & FER1L6 \\
\hline & $\mathrm{q} 24.21$ & 130632541 & 130857683 & 225,142 & 12.5 & & GSDMC \\
\hline 12 & q13.2 & 54405492 & 54500555 & 95,063 & 12.5 & CIP29 & CD63, GDF11, ORMDL2 \\
\hline 17 & $\mathrm{q} 12$ & 34260921 & 34473439 & 212,518 & 12.5 & $\begin{array}{l}\text { RPL23, PLXDC1, } \\
\text { LASP1 }\end{array}$ & $\mathrm{FBXO47}$ \\
\hline \multirow[t]{2}{*}{19} & q13.33 & 55918797 & 56055048 & 136,251 & 12.5 & KLK15, KLK3 & CLEC11A, GPR32, ACPT, C19orf48, KLK1 \\
\hline & q13.42 & 60568830 & 60853735 & 284,905 & 12.5 & IL11, UBE2S & $\begin{array}{l}\text { TMEM190, RPL28, ZNF579, FIZ1, ZNF524, ZNF580, } \\
\text { ZNF581, CCDC106 }\end{array}$ \\
\hline 20 & $q 12$ & 39100100 & 39358266 & 258,166 & 15.0 & PLCG1, TOP1 & PRO0628, ZHX3 \\
\hline
\end{tabular}

Most frequent gains in BRCAX tumors are highlighted in bold

revealing high inter-tumor heterogeneity at the genomic level. As stated in results, the higher frequency of deletions or gains was $22.5 \%$ among BRCAX tumors. Within the identified alterations in BRCAX tumors, several regions have been previously identified in similar studies for non-BRCA1/2 familial cancer, such as loss in $11 \mathrm{q}$ and $16 \mathrm{q}$, and gains in $1 \mathrm{q}$ and $8 \mathrm{q}$ $[14,55]$.

In relation to tumors with BRCA $1 / 2$ germline mutations, frequency of recurrent alterations rises to $75 \%$ within $B R C A 2$ tumors, and $66 \%$ within $B R C A 1$ tumors. In addition to the most recurrent alterations, our work describes the presence of genomic alterations present only in the BRCA1/2 mutated tumors. Previous reports have described common alterations in BRCA1 and $B R C A 2$ tumors $[8,13,14,55]$, that are also present in sporadic or familial BRCAX tumors, although in a lower frequency. Within the regions described in the literature, loss of $4 \mathrm{q}, 3 \mathrm{p}, 12 \mathrm{q}$ in BRCA1 tumors, and loss of $11 \mathrm{q}$ and $13 \mathrm{q}$ for $B R C A 2$ are recurrent. In our tumors all the previous alterations were found, being loss of $4 \mathrm{q}$ and 11q present only in our BRCA mutated tumors. Among the regions described as altered for BRCA1/2 tumors in our study we found several genes that have been previously associated with relevant cellular processes such as DNA repair, cell growth and apoptosis.

Clustering of hereditary tumors using genomic alterations revealed that the tumors of the Yellow cluster 
Table 4 Genomic deletions and gains shared by 2 or more germline mutated tumors

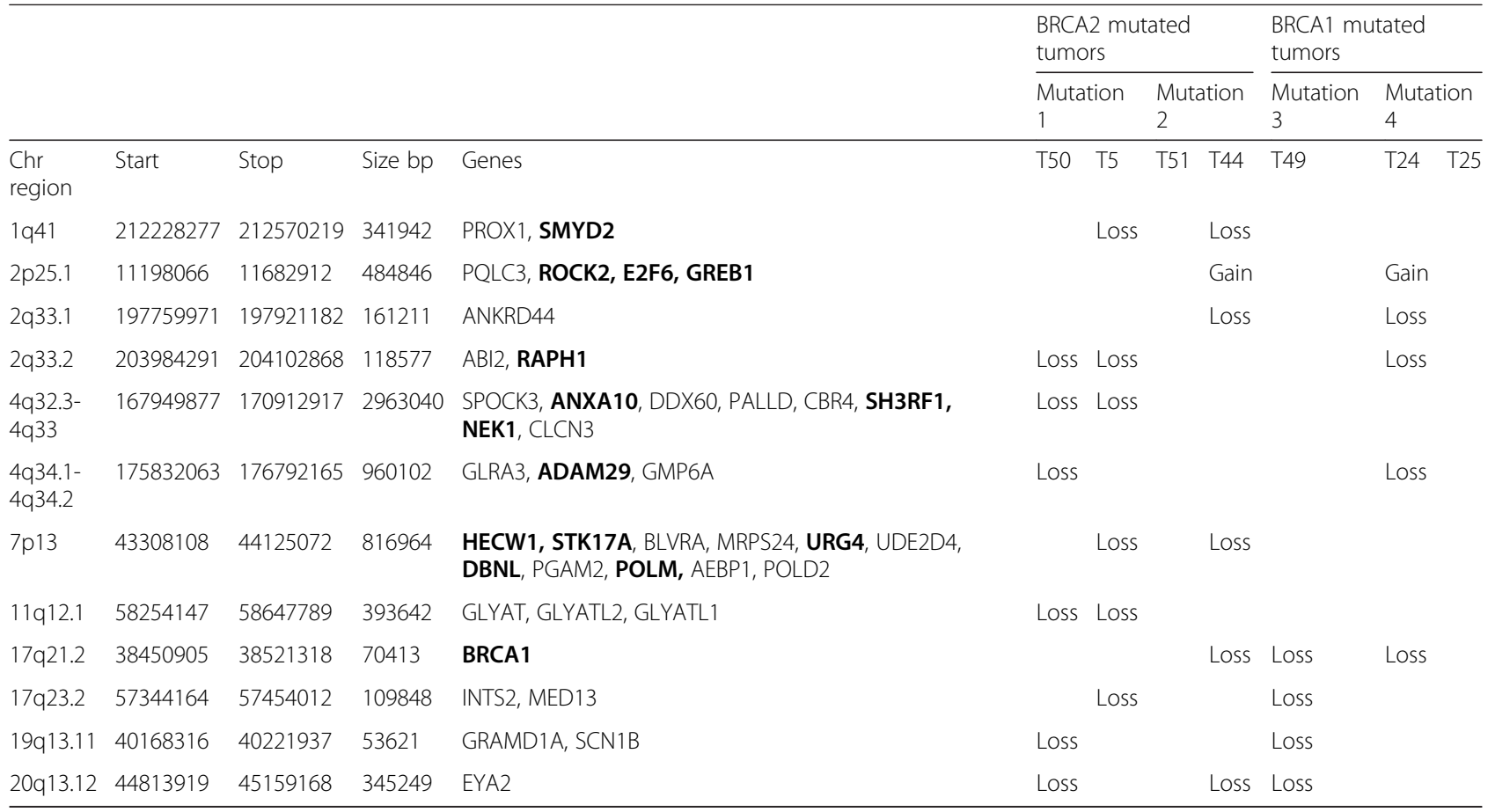

In bold are highlighted cancer associated genes found in genomic losses and gains present only in BRCA1 and BRCA2 tumors

have significant poor overall survival compared to the rest of the groups (Fig. 2b). In this relation, DARC and $D A G 1$ genes, contained in the frequent genomic losses in the Yellow cluster, have been previously associated to poor survival. DAG1 encodes $\alpha$-Dystroglycan, a highly relevant glycoprotein that binds to laminin maintaining the correct organization of epithelial tissues [56]. On the other hand, $D A R C$ as a chemokine receptor has a major role in inflammation, a process commonly present during invasion of tumor cells. In this sense, the loss of expression of these two genes associated to a poor prognosis, maybe due to a higher incidence of metastasis in these patients [52-54]. In addition, as described in results the Yellow cluster present frequent a loss of $P L E-$ KHO1 and GDF11 genes, regulators of PI3K/AKT and EGF signaling, respectively. These two pathways have been extensively cited as highly activated in triple negative breast cancer tumors, which are well known for having a poor overall survival with respect to other breast cancer subtypes [57]. The contribution of the activation of PI3K/AKT and EGF pathways to poor survival has been related to the lower response and/or resistance to chemotherapy observed in patients $[58,59]$. Finally, we also found loss of CD63 (member of the tetraspanin family), an event previously associated to advanced stages of melanoma [60]. The involvement of CD63 in cancer metastasis and its loss in tumors described in this study, is in concordance with a poorer overall survival of patients in the yellow cluster. The Blue cluster have also interesting features, since losses found in this group involve genes related to the processing and presentation of immunogenic peptides, which are frequently downregulated in different types of cancer (Cluster analysis section in Results). Downregulation of these genes affect peptide characteristics and their transport to the endoplasmic reticulum for its binding by MHC class I proteins. In this regard, tumors presenting these deletions will have a possibility for treatment with specific immunotherapy.

We found significant differences in the number of alterations between clusters, having the Green cluster the lower instability compared with Blue, Yellow and Purple clusters. A previous work by Stefansson et al [13] analyzed 29 tumors defined as "with BRCA alterations" (BRCA1/2 mutation or BRCA1 hypermethylation/loss of expression) compared to 38 sporadic tumors without any BRCA alteration. These authors described 4 clusters of tumors, three of which present a high instability, like in our study. Among those three clusters, two were enriched in BRCA altered tumors presenting mainly big size losses. This is consistent with our results, since the Yellow cluster (6 tumors) having high genomic instability and characterized mainly by losses, is enriched in BRCA1 and BRCA2 mutated tumors (3/6 tumors). In addition to this concordance with Stefansson's results, regarding hereditary BRCA1 or 2 deficient tumors, we added to the knowledge the fact that this instable BRCA-enriched cluster has a poor overall survival, as mentioned in the previous paragraph. Our results in 


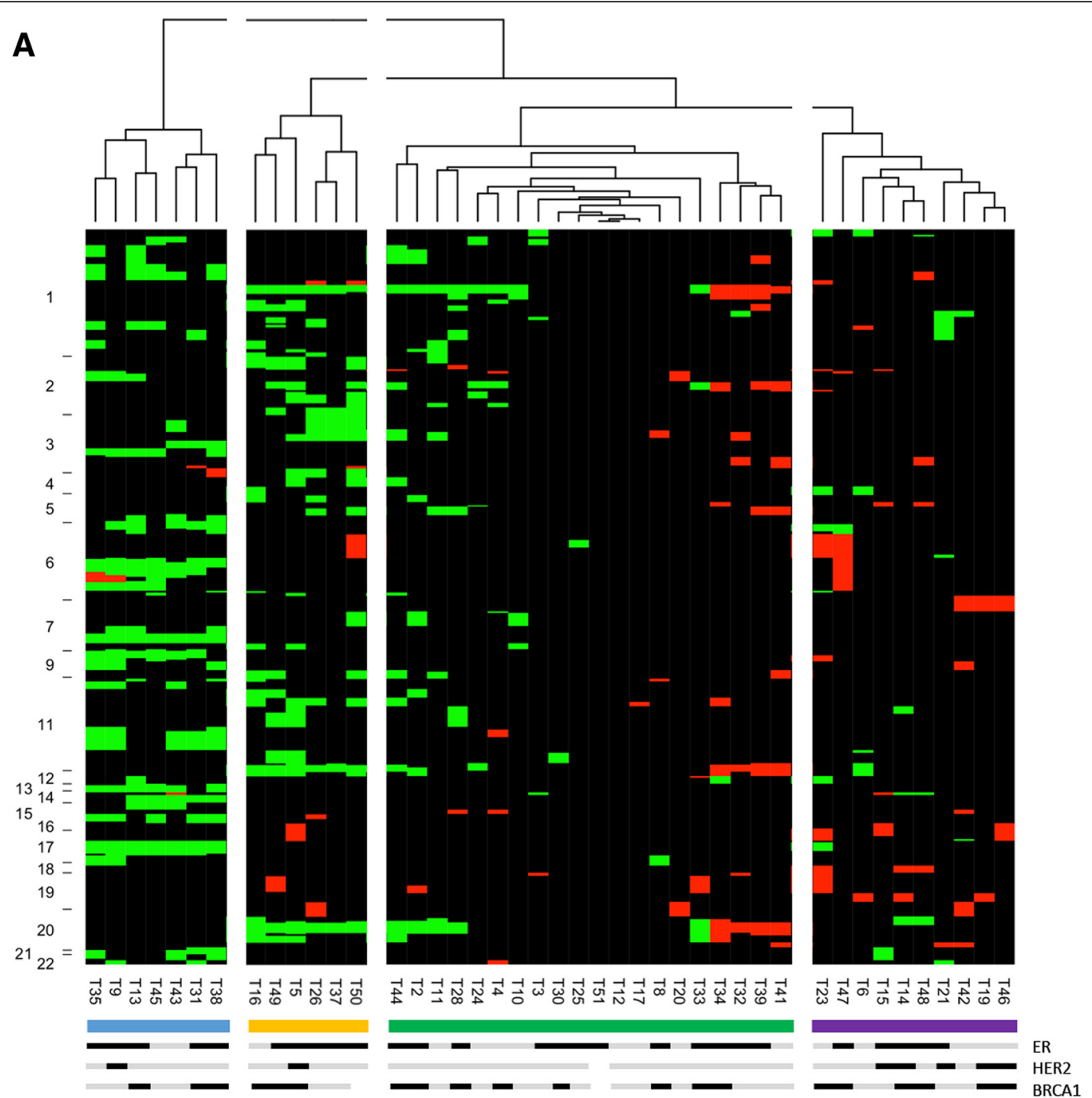

B

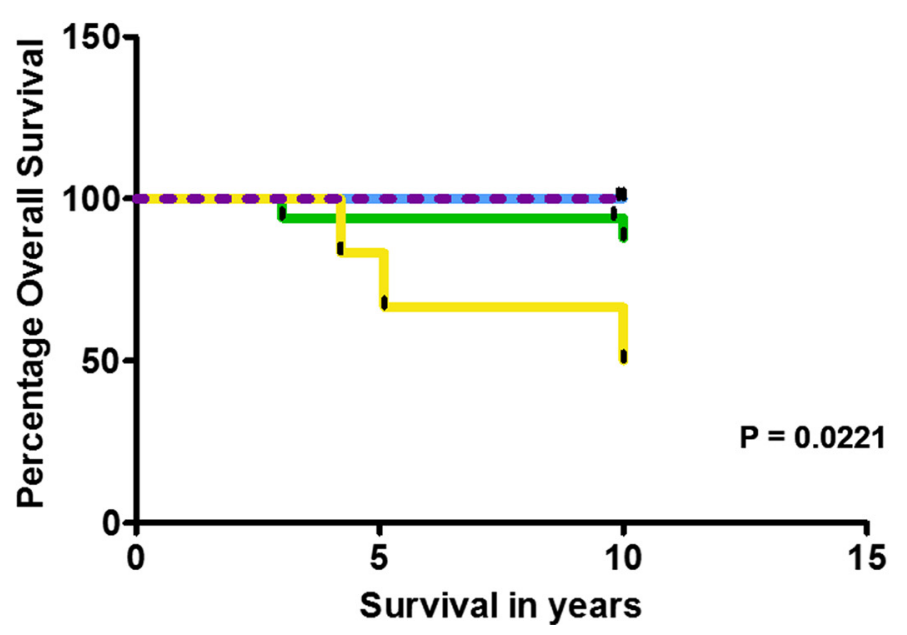

- Green (N=20)

- Blue ( $N=7)$

- Yelow $(\mathrm{N}=6)$

i. Purple $(\mathrm{N}=10)$

Fig. 2 (See legend on next page.) 
(See figure on previous page.)

Fig. 2 Cluster analysis of hereditary tumors. a Unsupervised hierarchical clustering for hereditary breast tumors. T1, T36, T22 and T29 were removed from the cluster as considered outliers. Numbers in the $Y$ - axis correspond to each chromosome and the marks in the $Y$-axis are the limits between chromosomes. Green boxes: losses, Red boxes: gains, Black boxes: no change. Four groups were identified and labeled with Blue, Yellow, Green and Purple lines under the picture. In addition, ER, HER2 and BRCA1 expression status is indicated below as follows: black: positive, grey: negative, white: no information. b Overall survival of the 4 clusters determined by Log-rank (Mantel-Cox) Test, $p<0.05$. Tumors from each cluster are represented with a respective color line

hereditary tumors are also consistent with Fridlyand et al [11], who described three groups of sporadic breast cancer tumors with differences in CNA number and type, and with survival.

Although we found in our tumors, genomic alterations previously described in the literature, these are present in a low proportion of tumors. In addition, it comes to our attention that tumors of the Green cluster, gathering almost half of our hereditary tumors, have a low number of alterations. Latin American populations, like the one in this study, constitute an admixture of Spanish and Amerindian individuals, being genetically different from breast cancer cases frequently analyzed in similar studies. These ethnic differences in conjunction with environmental factors may lead into differences in the molecular mechanisms of cancer progression among populations.

In our study, we included different pathological subtypes such as ductal and lobular in situ and invasive carcinomas. According to our results, these carcinomas are distributed across all clusters, indicating that in situ diseases are as heterogeneous as, and behave similar to, the invasive tumors.

BRCA1 silencing in sporadic and hereditary tumors have been described in the last years to be a relevant mechanism associated to breast cancer progression in patients with no germline mutation [16, 17]. In our study, small groups of BRCA1 not expressing tumors share common genomic alterations though the majority of tumors do not have the same genes affected. Nonetheless, the relevant cellular processes highlighted for these tumors revealed that the affected genes, although different, involve the same molecular pathways. This observation is in agreement with previous reports describing core affected pathways in pancreatic cancer [61, 62]. In addition, we identified genomic alterations and cellular processes shared by BRCA1 mutated and BRCA1 not expressing tumors. This is in line with the fact that some tumors, lacking germline mutations in BRCA1 show a BRCAness phenotype, implying that they could have a cancer progression program similar to BRCA1 mutated tumors.

The results obtained for BRCA1 not expressing tumors suggest a more relevant contribution of BRCA1 functional deficiency to the general genomic instability of the tumors than to the development of specific alterations. As observed, none of the tumor clusters are characterized by a particular BRCA1 expression status, but they do carry common alterations (Fig. 2a). This evidence may reflect that the consequences of BRCA1 functional deficiency depend on the genetic background of the tumors, the mechanism of inactivation, or the moment at which this event occurs. Moreover, it is necessary to determine whether other alterations of BRCA1 function, such as cytoplasmic retention, somatic mutations or post-translational regulation by miRNAs may contribute to the particular genomic profiles observed in each cluster.

Array CGH have been used in recent years to get relevant information for clinical trials. Two prospective trials, SAFIR01 and MOSCATO, intend to destine patients to different targeted therapies depending on genomic gains and somatic mutations affecting relevant targets for therapy. In these studies, amplifications of low recurrence involving genes such as EGFR, FGFR and FGF ligands, AKT, PIK3CA and IGF1R are suitable markers for

Table 5 Gene ontology enrichment in different groups of hereditary tumors

\begin{tabular}{|c|c|}
\hline Tumor groups & Enriched Gene Ontologies \\
\hline BRCA1/2 mutated & $\begin{array}{l}\text { Regulation of cytoskeleton organization, Negative regulation of mammary epithelial cell proliferation, Protein modification } \\
\text { process, Apoptosis, Cell cycle regulation, RNA transcription and processing, DNA damage repair, DNA packaging }\end{array}$ \\
\hline $\begin{array}{l}\text { BRCA1 not } \\
\text { expressing }\end{array}$ & $\begin{array}{l}\text { Alpha aminoacid metabolic/biosynthetic processes, Protein citrullination and Citrulline metabolism, Proteolysis, Transcription, } \\
\text { Chromosome segregation and chromatin organization, Apoptosis }\end{array}$ \\
\hline BRCA1 expressing & No enrichment was found \\
\hline Blue cluster & Antigen processing and presentation (13 GO Terms), Intracellular transport \\
\hline Yellow cluster & Cytokine signaling, Collagen metabolic processes and Extracellular matrix organization \\
\hline Purple cluster & Calcium-independent cell-cell adhesion \\
\hline Green cluster & No enrichment was found \\
\hline
\end{tabular}


moderate or good antitumor response (stable disease or remission) to specific inhibitor for these pathways. In our study (data not shown), amplification of $A K T, P I K 3 C A$ and FGF receptors and ligands were observed in BRCA1 not expressing tumors, opening a new therapeutic opportunity for tumors with a BRCAness phenotype. In this relation, it has already been demonstrated in triple negative breast cancer cell lines, that combining PI3K and EGFR inhibitors produces a better response than each inhibitor alone [63] becoming a promising strategy for BRCAness tumors treatment. In addition, a group of our tumors (Yellow cluster) exhibit deletions of PLEKHO1 and GDF11, which products regulate PI3K and EGF signaling pathways. Patients carrying this type of tumors, showing a poor overall survival, could be good candidates for the combined therapy mentioned before. These therapies may bring an alternative treatment to patients carrying BRCAness tumors, or could be used in combination with PARP inhibitors.

\section{Conclusion}

Our results support the fact that BRCA1 expression in tumors should be used as a marker for BRCAness and for selection of these patients for synthetic lethality approaches such as treatment with PARP inhibitors. In addition, the identification of specific alterations in breast tumors associated with poor survival, immune response or with a BRCAness phenotype will allow the use of a more personalized treatment in these patients.

\section{Abbreviations \\ aCGH: Array based Comparative Genomic Hybridization; ADM-1: Aberration Detection Method-1; ASCO: American Society of Clinical Oncology; BRCAX: Hereditary breast cancer without BRCA1 or BRCA2 germline mutations; CAP: College of American Pathologists; CNV: Copy Number Variation; ER: Estrogen Receptor; FFPE: Formalin-Fixed Paraffin Embedded; H\&E: Hematoxylin-Eosin staining.}

\section{Competing interests}

Authors have nothing to disclose.

\section{Authors' contributions}

CA carried out the Array CGH analyses, participated in the design and write the article. AA performed all bioinformatics analysis of Array CGH data and participated in results discussion. TT performed the statistical analysis of survival and in the discussion of the results. ER, DM and AM contributed to the discussion of the design and/or data processing. LS and AC performed microdissection and immunohistochemical analyses of ER and HER2. MC and MM selected patients and contributed to writing the manuscript. All authors read and approved the final manuscript. PC conceived the study,

participated in its design and coordination, and help to draft the manuscript.

\section{Acknowledgments}

We thank FONDECYT grants 1040779 and 1120200, CONICYT and Fulbright Foundation for C. Alvarez fellowships. This project has been funded in part with federal funds from the National Cancer Institute, National Institutes of Health, under contract N01-CO-12400. The content of this publication does not necessarily reflect the views or policies of the Department of Health and Human Services, nor does mention of trade names, commercial products, or organizations imply endorsement by the U.S. Government.

\section{Author details}

'Department of Cellular and Molecular Biology, Faculty of Biological Sciences, Pontificia Universidad Católica de Chile, Santiago, Chile. ${ }^{2}$ Mathomics, Center for Mathematical Modeling (UMI 2807 CNRS) and Center for Genome Regulation (Fondap 15090007), University of Chile, Santiago, Chile. ${ }^{3}$ Laboratory of Molecular Technology Advanced Technology Program, SAIC-Frederick, Inc., National Cancer Institute-Frederick, Frederick, MD, USA. ${ }^{4}$ Department of Anatomo-Pathology, Faculty of Medicine, Pontificia Universidad Católica de Chile, Santiago, Chile. ${ }^{5}$ Cancer Center, Faculty of Medicine, Pontificia Universidad Católica de Chile, Santiago, Chile. ${ }^{6} \mathrm{Clinica}$ Las Condes, Santiago, Chile. ${ }^{7}$ Department of Mathematical Engineering, University of Chile, Santiago, Chile. ${ }^{8}$ Department of Molecular Biology and Genetics, Faculty of Science, Istanbul University, Istanbul 34134, Turkey.

Received: 15 July 2015 Accepted: 8 March 2016

Published online: 15 March 2016

\section{References}

1. Teschendorff AE, Caldas C. The breast cancer somatic 'muta-ome': tackling the complexity. Breast Cancer Res. 2009;11(2):301. doi:10.1186/bcr2236.

2. Esteller M. CpG island hypermethylation and tumor suppressor genes: a booming present, a brighter future. Oncogene. 2002;21(35):5427-40. doi:10.1038/sj.onc.1205600.

3. Lerebours F, Lidereau R. Molecular alterations in sporadic breast cancer. Crit Rev Oncol Hematol. 2002;44(2):121-41.

4. Vogelstein B, Papadopoulos N, Velculescu VE, Zhou S, Diaz Jr LA, Kinzler KW. Cancer genome landscapes. Science. 2013;339(6127):1546-58. doi:10.1126/ science.1235122.

5. Davies JJ, Wilson IM, Lam WL. Array CGH technologies and their applications to cancer genomes. Chromosome Res. 2005;13(3):237-48. doi:10.1007/s10577-005-2168-x.

6. Pinkel D, Albertson DG. Array comparative genomic hybridization and its applications in cancer. Nat Genet. 2005;37(Suppl):S11-7. doi:10.1038/ng1569.

7. Gronwald J, Jauch A, Cybulski C, Schoell B, Bohm-Steuer B, Lener M, et al. Comparison of genomic abnormalities between BRCAX and sporadic breast cancers studied by comparative genomic hybridization. Int J Cancer. 2005;114(2):230-6. doi:10.1002/ijc.20723.

8. Jonsson G, Naylor TL, Vallon-Christersson J, Staaf J, Huang J, Ward MR, et al. Distinct genomic profiles in hereditary breast tumors identified by arraybased comparative genomic hybridization. Cancer Res. 2005;65(17):7612-21.

9. Naylor TL, Greshock J, Wang Y, Colligon T, Yu QC, Clemmer V, et al. High resolution genomic analysis of sporadic breast cancer using array-based comparative genomic hybridization. Breast Cancer Res. 2005;7(6):R1186-98. doi:10.1186/bcr1356

10. Nessling M, Richter K, Schwaenen C, Roerig P, Wrobel G, Wessendorf S, et al Candidate genes in breast cancer revealed by microarray-based comparative genomic hybridization of archived tissue. Cancer Res. 2005;65(2):439-47.

11. Fridlyand J, Snijders AM, Ylstra B, Li H, Olshen A, Segraves R, et al. Breast tumor copy number aberration phenotypes and genomic instability. BMC Cancer. 2006;6:96. doi:10.1186/1471-2407-6-96.

12. van Beers EH, van Welsem T, Wessels LF, Li Y, Oldenburg RA, Devilee $P$, et al. Comparative genomic hybridization profiles in human BRCA1 and BRCA2 breast tumors highlight differential sets of genomic aberrations. Cancer Res. 2005;65(3):822-7.

13. Stefansson OA, Jonasson JG, Johannsson OT, Olafsdottir K, Steinarsdottir M, Valgeirsdottir $\mathrm{S}$, et al. Genomic profiling of breast tumours in relation to BRCA abnormalities and phenotypes. Breast Cancer Res. 2009;11(4):R47. doi:10.1186/bcr2334

14. Alvarez S, Diaz-Uriarte R, Osorio A, Barroso A, Melchor L, Paz MF, et al. A predictor based on the somatic genomic changes of the BRCA1/BRCA2 breast cancer tumors identifies the non-BRCA1/BRCA2 tumors with BRCA1 promoter hypermethylation. Clin Cancer Res. 2005;11(3):1146-53.

15. Melchor L, Honrado E, Garcia MJ, Alvarez S, Palacios J, Osorio A, et al. Distinct genomic aberration patterns are found in familial breast cancer associated with different immunohistochemical subtypes. Oncogene. 2008;27(22):3165-75. doi:10.1038/sj.onc.1210975.

16. Birgisdottir V, Stefansson OA, Bodvarsdottir SK, Hilmarsdottir H, Jonasson JG, Eyfjord JE. Epigenetic silencing and deletion of the BRCA1 gene in sporadic breast cancer. Breast Cancer Res. 2006;8(4):R38. doi:10.1186/bcr1522. 
17. Tapia T, Smalley SV, Kohen P, Munoz A, Solis LM, Corvalan A, et al. Promoter hypermethylation of BRCA1 correlates with absence of expression in hereditary breast cancer tumors. Epigenetics. 2008;3(3):157-63.

18. Tan X, Peng J, Fu Y, An S, Rezaei K, Tabbara S, et al. miR-638 mediated regulation of BRCA1 affects DNA repair and sensitivity to UV and cisplatin in triple-negative breast cancer. Breast Cancer Res. 2014;16(5):435. doi:10.1186/ s13058-014-0435-5.

19. Garcia Al, Buisson M, Bertrand P, Rimokh R, Rouleau E, Lopez BS, et al. Down-regulation of BRCA1 expression by miR-146a and miR-146b-5p in triple negative sporadic breast cancers. EMBO Mol Med. 2011;3(5):279-90. doi:10.1002/emmm.201100136.

20. Moskwa P, Buffa FM, Pan Y, Panchakshari R, Gottipati P, Muschel RJ, et al. miR182-mediated downregulation of BRCA1 impacts DNA repair and sensitivity to PARP inhibitors. Mol Cell. 2011;41(2):210-20. doi:10.1016/j.molcel.2010.12.005.

21. Lips EH, Mulder L, Oonk A, van der Kolk LE, Hogervorst FBL, Imholz ALT, et al. Triple-negative breast cancer: BRCAness and concordance of clinical features with BRCA1-mutation carriers. Br J Cancer. 2013;108(10):2172-7. doi:10.1038/bjc.2013.144.

22. Joosse SA, Brandwijk Kl, Mulder L, Wesseling J, Hannemann J, Nederlof PM. Genomic signature of BRCA1 deficiency in sporadic basal-like breast tumors. Genes Chromosomes Cancer. 2011;50(2):71-81. doi:10.1002/gcc.20833.

23. Gallardo M, Silva A, Rubio L, Alvarez C, Torrealba C, Salinas M, et al. Incidence of BRCA1 and BRCA2 mutations in 54 Chilean families with breast/ovarian cancer, genotype-phenotype correlations. Breast Cancer Res Treat. 2006;95(1):81-7. doi:10.1007/s10549-005-9047-1.

24. Eden E, Navon R, Steinfeld I, Lipson D, Yakhini Z. GOrilla: a tool for discovery and visualization of enriched $\mathrm{GO}$ terms in ranked gene lists. BMC Bioinformatics. 2009;10:48. doi:10.1186/1471-2105-10-48.

25. Da Huang W, Sherman BT, Lempicki RA. Systematic and integrative analysis of large gene lists using DAVID bioinformatics resources. Nat Protoc. 2009;4(1):44-57

26. Tokuda E, Fujita N, Oh-hara T, Sato S, Kurata A, Katayama R, et al. Casein kinase 2-interacting protein-1, a novel Akt pleckstrin homology domain-interacting protein, down-regulates PI3K/Akt signaling and suppresses tumor growth in vivo. Cancer Res. 2007;67(20):9666-76. doi:10.1158/0008-5472.can-07-1050.

27. Peltonen HM, Haapasalo A, Hiltunen M, Kataja V, Kosma VM, Mannermaa A. Gamma-secretase components as predictors of breast cancer outcome. PLoS One. 2013:8(11):e79249. doi:10.1371/journal.pone.0079249.

28. Zheng F, Hasim A, Anwer J, Niyaz M, Sheyhidin I. LMP gene promoter hypermethylation is a mechanism for its down regulation in Kazak's esophageal squamous cell carcinomas. Mol Biol Rep. 2013;40(3):2069-75. doi:10.1007/s11033-012-2138-2

29. Callahan MJ, Nagymanyoki Z, Bonome T, Johnson ME, Litkouhi B, Sullivan $\mathrm{EH}$, et al. Increased HLA-DMB expression in the tumor epithelium is associated with increased CTL infiltration and improved prognosis in advanced-stage serous ovarian cancer. Clin Cancer Res. 2008;14(23):7667-73. doi:10.1158/1078-0432.ccr-08-0479.

30. Wong TS, Rajagopalan S, Townsley FM, Freund SM, Petrovich M, Loakes D, et al. Physical and functional interactions between human mitochondrial single-stranded DNA-binding protein and tumour suppressor p53. Nucleic Acids Res. 2009;37(2):568-81. doi:10.1093/nar/gkn974.

31. Wikman H, Westphal L, Schmid F, Pollari S, Kropidlowski J, Sielaff-Frimpong $B$, et al. Loss of CADM1 expression is associated with poor prognosis and brain metastasis in breast cancer patients. Oncotarget. 2014;5(10):3076-87.

32. Roubin R, Acquaviva C, Chevrier V, Sedjai F, Zyss D, Birnbaum D, et al. Myomegalin is necessary for the formation of centrosomal and Golgi-derived microtubules. Biol Open. 2013;2(2):238-50. doi:10.1242/bio.20123392.

33. Shimada H, Kuboshima M, Shiratori T, Nabeya Y, Takeuchi A, Takagi H, et al. Serum anti-myomegalin antibodies in patients with esophageal squamous cell carcinoma. Int J Oncol. 2007;30(1):97-103.

34. Hsing $\mathrm{CH}$, Cheng HC, Hsu YH, Chan CH, Yeh CH, Li CF, et al. Upregulated IL-19 in breast cancer promotes tumor progression and affects clinical outcome. Clin Cancer Res. 2012;18(3):713-25. doi:10.1158/1078-0432.ccr-11-1532.

35. Hsu YH, Wei CC, Shieh DB, Chan CH, Chang MS. Anti-IL-20 monoclonal antibody alleviates inflammation in oral cancer and suppresses tumor growth. Mol Cancer Res. 2012;10(11):1430-9. doi:10.1158/1541-7786.mcr-12-0276.

36. Chen YY, Li CF, Yeh CH, Chang MS, Hsing CH. Interleukin-19 in breast cancer. Clin Dev Immunol. 2013;2013:294320. doi:10.1155/2013/294320.

37. Hancer VS, Diz-Kucukkaya R, Aktan M. Overexpression of Fc mu receptor (FCMR, TOSO) gene in chronic lymphocytic leukemia patients. Med Oncol. 2012;29(2):1068-72. doi:10.1007/s12032-011-9821-3.
38. Mosca E, Alfieri R, Merelli I, Viti F, Calabria A, Milanesi L. A multilevel data integration resource for breast cancer study. BMC Syst Biol. 2010;4:76. doi:10.1186/1752-0509-4-76.

39. Ponten $\mathrm{F}$, Jirstrom $\mathrm{K}$, Uhlen $\mathrm{M}$. The human protein atlas-a tool for pathology. J Pathol. 2008;216(4):387-93. doi:10.1002/path.2440.

40. MacDonald G, Stramwasser M, Mueller CR. Characterization of a negative transcriptional element in the BRCA1 promoter. Breast Cancer Res. 2007;9(4):R49. doi:10.1186/bcr1753.

41. Tang $H$, Liu P, Yang L, Xie X, Ye F, Wu M, et al. miR-185 suppresses tumor proliferation by directly targeting E2F6 and DNMT1 and indirectly upregulating BRCA1 in triple-negative breast cancer. Mol Cancer Ther. 2014;13(12):3185-97. doi:10.1158/1535-7163.mct-14-0243.

42. Chen Y, Chen CF, Chiang HC, Pena M, Polci R, Wei RL, et al. Mutation of NIMA-related kinase 1 (NEK1) leads to chromosome instability. Mol Cancer. 2011;10(1):5. doi:10.1186/1476-4598-10-5.

43. Xu Z, Kukekov NV, Greene LA. POSH acts as a scaffold for a multiprotein complex that mediates JNK activation in apoptosis. EMBO J. 2003;22(2):252-61. doi:10.1093/emboj/cdg021.

44. Kim J, Kim MA, Jee CD, Jung EJ, Kim WH. Reduced expression and homozygous deletion of annexin A10 in gastric carcinoma. Int J Cancer. 2009;125(8):1842-50. doi:10.1002/ijc.24541.

45. Chang PH, Hwang-Verslues WW, Chang YC, Chen CC, Hsiao M, Jeng YM, et al. Activation of Robo1 signaling of breast cancer cells by Slit2 from stromal fibroblast restrains tumorigenesis via blocking PI3K/Akt/ beta-catenin pathway. Cancer Res. 2012;72(18):4652-61. doi:10.1158/ 0008-5472.can-12-0877.

46. Alvarez C, Tapia T, Cornejo V, Fernandez W, Munoz A, Camus M, et al. Silencing of tumor suppressor genes RASSF1A, SLIT2, and WIF1 by promoter hypermethylation in hereditary breast cancer. Mol Carcinog. 2013;52(6):47587. doi:10.1002/mc.21881.

47. Kratochvilova K, Horak P, Esner M, Soucek K, Pils D, Anees M, et al. Tumor suppressor candidate 3 (TUSC3) prevents the epithelial-tomesenchymal transition and inhibits tumor growth by modulating the endoplasmic reticulum stress response in ovarian cancer cells. Int J Cancer. 2015;137(6):1330-40. doi:10.1002/ijc.29502.

48. Wang C, Wang J, Liu H, Fu Z. Tumor suppressor DLC-1 induces apoptosis and inhibits the growth and invasion of colon cancer cells through the Wnt/beta-catenin signaling pathway. Oncol Rep. 2014:31(5):2270-8. doi:10.3892/or.2014.3057.

49. Yan SM, Tang JJ, Huang CY, Xi SY, Huang MY, Liang JZ, et al. Reduced expression of ZDHHC2 is associated with lymph node metastasis and poor prognosis in gastric adenocarcinoma. PLoS One. 2013;8(2):e56366. doi:10.1371/journal.pone.0056366.

50. Rodrigues-Ferreira S, Di Tommaso A, Dimitrov A, Cazaubon S, Gruel N Colasson $\mathrm{H}$, et al. 8p22 MTUS1 gene product ATIP3 is a novel antimitotic protein underexpressed in invasive breast carcinoma of poor prognosis. PLoS One. 2009;4(10):e7239. doi:10.1371/journal.pone. 0007239.

51. Ye F, Tang H, Liu Q, Xie X, Wu M, Liu X, et al. miR-200b as a prognostic factor in breast cancer targets multiple members of RAB family. J Transl Med. 2014;12:17. doi:10.1186/1479-5876-12-17.

52. Wang J, Ou ZL, Hou YF, Luo JM, Shen ZZ, Ding J, et al. Enhanced expression of Duffy antigen receptor for chemokines by breast cancer cells attenuates growth and metastasis potential. Oncogene. 2006;25(54):7201-11. doi:10.1038/sj.onc.1209703.

53. Zeng XH, Ou ZL, Yu KD, Feng LY, Yin WJ, Li J, et al. Coexpression of atypical chemokine binders (ACBs) in breast cancer predicts better outcomes. Breast Cancer Res Treat. 2011;125(3):715-27. doi:10.1007/s10549-010-0875-2.

54. Sgambato A, Migaldi M, Montanari M, Camerini A, Brancaccio A, Rossi $\mathrm{G}$, et al. Dystroglycan expression is frequently reduced in human breast and colon cancers and is associated with tumor progression. Am J Pathol. 2003;162(3):849-60. doi:10.1016/s0002-9440(10)63881-3.

55. Melchor L, Honrado E, Huang J, Alvarez S, Naylor TL, Garcia MJ, et al. Estrogen receptor status could modulate the genomic pattern in familial and sporadic breast cancer. Clin Cancer Res. 2007;13(24):730513. doi:10.1158/1078-0432.ccr-07-0711.

56. Brennan PA, Jing J, Ethunandan M, Górecki D. Dystroglycan complex in cancer. Eur J Surg Oncol (EJSO). 2004;30(6):589-92. http://dx.doi.org/10.1016/ j.ejso.2004.03.014.

57. Network CGA. Comprehensive molecular portraits of human breast tumours. Nature. 2012;490(7418):61-70. doi:10.1038/nature11412. 
58. Navolanic PM, Steelman LS, McCubrey JA. EGFR family signaling and its association with breast cancer development and resistance to chemotherapy (Review). Int J Oncol. 2003;22(2):237-52.

59. Kim EK, Kim JH, Kim HA, Seol H, Seong MK, Lee JY, et al. Phosphorylated S6 kinase-1: a breast cancer marker predicting resistance to neoadjuvant chemotherapy. Anticancer Res. 2013;33(9):4073-9.

60. Lupia A, Peppicelli S, Witort E, Bianchini F, Carloni V, Pimpinelli N, et al. CD63 tetraspanin is a negative driver of epithelial-to-mesenchymal transition in human melanoma cells. J Invest Dermatol. 2014;134(12):2947-56. doi:10.1038/ jid.2014.258.

61. Jones S, Zhang X, Parsons DW, Lin JC, Leary RJ, Angenendt P, et al. Core signaling pathways in human pancreatic cancers revealed by global genomic analyses. Science. 2008;321(5897):1801-6. doi:10.1126/science. 1164368.

62. Comprehensive molecular characterization of human colon and rectal cancer. Nature. 2012;487(7407):330-7. doi:10.1038/nature11252.

63. Tao JJ, Castel P, Radosevic-Robin N, Elkabets M, Auricchio N, Aceto N, et al. Antagonism of EGFR and HER3 enhances the response to inhibitors of the PI3K-Akt pathway in triple-negative breast cancer. Sci Signal. 2014;7(318): ra29. doi:10.1126/scisignal.2005125.

Submit your next manuscript to BioMed Central and we will help you at every step:

- We accept pre-submission inquiries

- Our selector tool helps you to find the most relevant journal

- We provide round the clock customer support

- Convenient online submission

- Thorough peer review

- Inclusion in PubMed and all major indexing services

- Maximum visibility for your research

Submit your manuscript at www.biomedcentral.com/submit
Biomed Central 